\title{
INTEGRATING USER PREFERENCES INTO URBAN GREEN AND BLUE INFRASTRUCTURE PLANNING: INSIGHTS FROM HALLE, GERMANY AND STOCKHOLM, SWEDEN
}

\author{
LINA RÖSCHEL, MCKENNA DAVIS \& SANDRA NAUMANN \\ Ecologic Institute, Germany
}

\begin{abstract}
Ongoing urban densification and the resultant stress on socio-ecological systems necessitate the development of innovative strategies for safeguarding green and blue infrastructure (GBI) and the benefits it provides. Yet, while GBI is increasingly recognised as an effective tool to respond to urban challenges, outcomes are often less than ideal. The capacity of multifunctional natural areas to simultaneously address user preferences, answer municipal needs, and fulfil wider political obligations is far from being fully realised. The present article responds to this situation and highlights the Q-method as an effective approach for assessing and integrating user viewpoints on urban GBI and its benefits in urban decision-making and planning processes. The application of the Q-method with 227 participants in two case study sites - Halle, Germany and Stockholm, Sweden - forms the basis for our analysis and conclusions. Results indicate that four main stakeholder groups are present in each city, with each group having clear preferences for specific green and blue characteristics, such as areas shaded by trees, access to water for swimming, "wild" nature, and manicured grass fields. By establishing which features are shared across groups, urban planning processes can successfully integrate public subjectivity into decision-making processes and respond to user preferences. The Q-method can thereby support an optimised use of public funds in urban planning to ensure that user needs are met and public acceptance is high, while safeguarding critical GBI benefits. This research was carried out as part of the ENABLE project, funded through the BiodivERsA COFUND call for research proposals.
\end{abstract}

Keywords: green infrastructure, sustainable urban planning, Q-method, user preferences, Halle, Stockholm.

\section{INTRODUCTION}

While Europe's population remains largely stagnant or declining [1], the trend towards urbanisation is increasing. Cities are now home to nearly $75 \%$ of the European Union population [2] while the urban population is expected to increase to $84 \%$ by 2050 [3]. This increasing densification has resulted in a limited availability of physical space for the built environment and conversion of natural areas to grey infrastructure [4]. These processes coupled with environmental pressures such as climate change and pollution place severe strains on the socio-ecological systems and exacerbate the degradation of natural habitats. Ecosystem service provisioning in urban areas is consequently in jeopardy [5], with repercussions for human health and well-being [6]-[9], biodiversity [10]-[12], social cohesion and equity [13], [14], and city resilience [15]. Populations facing such local challenges often lack opportunities to express their needs, contribute their knowledge or be involved in developing and implementing suitable solutions [16], [17]. At the same time, city administrations frequently lack tools to address these problems [18], [19] while taking into account the needs of all stakeholder groups.

These conditions necessitate the development of innovative strategies for safeguarding green and blue infrastructure (GBI) and the potential benefits it provides [20], while integrating the needs and views of affected populations into related planning processes [21]. 
Yet while GBI - or the "strategically planned network of natural and semi-natural (green and blue (i.e. water)) areas" [22] - is increasingly recognised as an effective tool to respond to urban challenges [22], [23], a mismatch remains between its potential and current delivery [24]. In particular, the capacity of these natural areas to be multifunctional in provisioning economic, environmental and socio-cultural benefits while also addressing user preferences, answering municipal needs and fulfilling wider political obligations is far from being fully realised [25].

Optimising a city's ability to deliver diverse benefits is a shared aim amongst policy makers and urban planners alike. However, a biased focus on delivering benefits which offer monetary gain, such as cost saving for climate adaptation and improved attractiveness for investors, tend to dominate municipal decision-making processes [26]. This approach to green space planning can indeed fulfil legal requirements and reach single policy-oriented targets but neglects the potential of green and blue spaces to deliver on multiple targets while also providing benefits for key stakeholders - i.e. the GBI users. To be effective and reach its potential, GBI thus requires embedding into decision-making through integrated planning. Efforts to gain user preferences as input for collaboratively defining sustainability goals and co-developing GBI design are an important component of this process [6], [27].

The present article responds to this need and highlights the Q-method as a practical approach for assessing and integrating user viewpoints on urban GBI and its benefits in urban decision-making and planning processes. We highlight the importance of the subjective opinions of urban green space users in terms of designing GBI elements and present the Q-method as a beneficial tool to determine what different user groups of a space determine most valuable in order to secure a space that will be enjoyed by a maximum of potential users, while also fulfilling municipal needs.

Within the project ENABLE (Enabling Green and Blue Infrastructure Potential in Complex Social-Ecological Regions), the Q-method was adapted for urban green spaces in Stockholm and Halle to identify different user groups of the respective areas as well as shared preferences for GBI elements. This paper presents insights from the Q-application, focusing strongly on the potential application of the results for policy making and the planning of urban green and blue areas. Specifically, we focus on providing answers to the following two questions:

- How can the Q-method be used to identify commonalities and differences in the perspectives and priorities of urban green space users?

- How can identified commonalities and differences among groups of urban green space users serve as the basis for improved urban green space planning?

\section{METHODOLOGY}

\subsection{Case study context}

This study focuses on an area of Halle in Germany (Halle Neustadt) and of Stockholm in Sweden (Flaten). Both areas are case studies in the ENABLE project, within which this research was conducted (see Acknowledgements). Their dissimilar population demographics, history of public participation in planning, and current state of development make them particularly interesting to explore societal preferences for cultural ecosystem services provided by GBI. 


\subsubsection{Halle, Germany: Halle Neustadt}

The city of Halle, located in eastern Germany, is subject to new construction sites on unsealed areas and brownfields due to population re-growth after a long period of shrinkage. Inner-city densification has led to increases in traffic, noise and air pollution, and its impact on human well-being. Our study was carried out in the small, neglected and partially abandoned area at the centre of a prefabricated building block in Halle Neustadt. Citizens' initiatives have supported the development of a public gardening space and skatepark adjacent to the study area, while the grassland in question has been left untouched. The local population has a high rate of unemployment, limited history with public participation in planning processes and low current use of the study area. Basic infrastructure like adequate lighting, seating options, and waste bins are not present.

\subsubsection{Stockholm, Sweden: Flaten}

The Flaten landscape is located in the southern part of the Stockholm region in Sweden and is subject to intense urbanisation by densification and sprawl. A formally protected nature reserve is the focus of our study, aiming to safeguard biological diversity and nature-based outdoor recreation. Given the rapidly changing landscape morphology and demography, the local authorities and civic actors initiated a number of processes and projects to explore ways to better integrate the protected area into the wider urbanising landscape. The goals are to make the area more accessible and ecologically sustainable and to address user needs. The landscape includes many physical barriers to ecological connectivity and accessibility as well as a large variety in the socio-economic status of the residents.

\subsection{Q-methodology: An introduction}

One of the core questions for the research methodology pertains to the means by which individuals' attitudes towards and preferences for cultural ecosystem services would be collected. The Q-methodology was selected as opposed to the more commonly employed Likert rating scales to avoid several shortcomings in the latter approach, namely: (1) failing to accurately reflect attitudes when individuals are asked to rate statements to which they previously gave no significant consideration (resulting in these items being ranked in the middle of the scale, instead of indicating a preference); (2) failing to measure true attitudes, which in reality are complex and not able to be represented on a linear one-dimensional scale; (3) using averages which have the potential to mask the true nature of the underlying distribution as well as individual responses.

The Q-methodology enables the quantification of human subjectivity through statistical interpretation, while simultaneously supporting in-depth, qualitative interpretation [28]. These outcomes of the Q-methodology are realised because the method asks respondents to sort a set of statements according to a single defined criterion (on our case "personal value") rather than seeking a "yes" or "no" or numeric rating scale response for each statement. As a consequence, the method avoids categorising people according to pre-defined response opinions and instead allows space for each individual's viewpoint to emerge through the analysis [28]. Finally, the Q-methodology does not infer the population and the proportion of people expressing certain views but reveals the range of views itself about the topic being explored [28], [29]. 


\subsection{Approach}

The Q-methodology was applied in Halle Neustadt and Flaten as a means to reveal the variety of citizen viewpoints on green, blue and other valued features within each area. The main steps of our approach followed classical Q-methodology design, consisting of:

1. Preparing the $\mathrm{Q}$-statements $(\mathrm{Q}$-set)

2. Developing the response board (Q-matrix)

3. Collecting the responses (Q-sorts)

4. Carrying out the analysis.

An initial set of circa 30 statements were formulated for each of the case study sites. In line with the focus of the ENABLE project, cultural ecosystem services (CES) were taken as the starting point in this step and used to identify site-specific GBI elements which could act as their proxy. A review of site-focused documents as well as scientific literature linking GBI and CES enabled the identification of relevant GBI and other features. These aspects were subsequently translated into a set of draft statements for each cases study site.

This draft statement underwent an internal evaluation to check for overlap, similarity and clarity in order to avoid duplications and confusion. Each statement was validated by Halle Neustadt and Flaten experts from within and outside of the ENABLE project consortium and once again amended as necessary. Lastly, the statements were simplified to be as short, clear and distinct as possible and to be consistent with our research aims [28]. The final Q-set consisted of tailored translated statements for Halle Neustadt (25 statements in German/English) and Flaten (25 statements in Swedish/English; see Table 1). This number served as the basis for designing and printing the Q-matrix (see Fig. 1).

On each case study site, participants ( $P$-set) were asked to sort statements into a normal distribution using the criterion "I value". Only one statement could be placed on each extreme end of the distribution (representing the least and most valued characteristics) while five statements could be placed in the centre (neutral value) position (see Fig. 1). At each case study site, the Q-matrix was set up at different physical locations within the site at various times of day for one week to increase representation of different demographics.

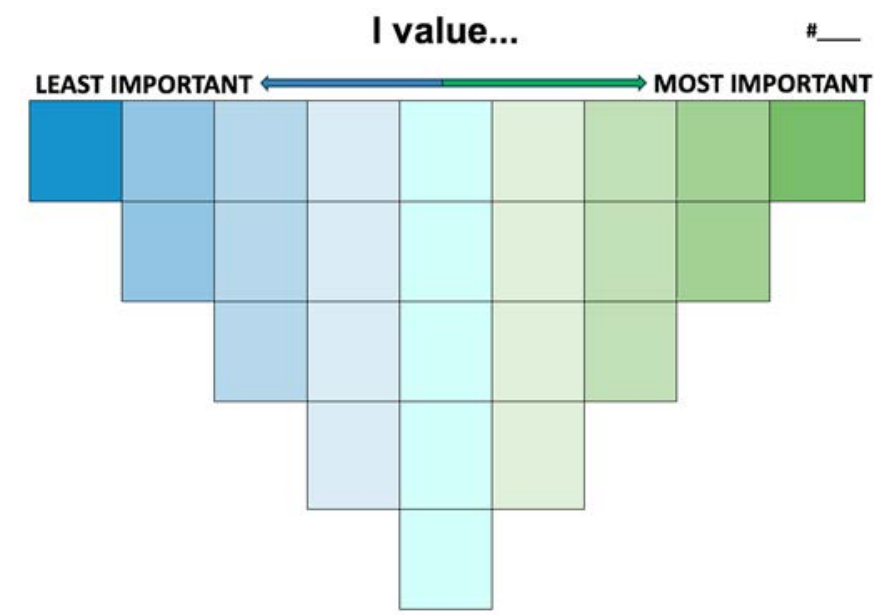

Figure 1: Q-matrix for 25 statements. 
Table 1: Q-sets of Flaten and Halle Neustadt case studies, with 25 statements each.

\begin{tabular}{|c|c|c|}
\hline ID & Q-set statements: Flaten & Q-set statements: Halle Neustadt \\
\hline 1 & $\begin{array}{l}\text { Staying overnight (e.g. camping or in } \\
\text { treehouses) }\end{array}$ & $\begin{array}{l}\text { Sport areas for e.g. bocce ball, table tennis, football, } \\
\text { skateboarding, etc. }\end{array}$ \\
\hline 2 & $\begin{array}{l}\text { Areas where kids can play (e.g. playgrounds, } \\
\text { sandboxes, fields) }\end{array}$ & $\begin{array}{l}\text { Using the area for everyday activities, like going for } \\
\text { walks, walking the dog, or jogging }\end{array}$ \\
\hline 3 & $\begin{array}{l}\text { Access to swimming facilities (bridges, diving } \\
\text { tower, showers) }\end{array}$ & $\begin{array}{l}\text { Infrastructure suitable for the elderly and disabled } \\
\text { (e.g. paved paths, barrier-free access, raised plant } \\
\text { beds) }\end{array}$ \\
\hline 4 & $\begin{array}{l}\text { Using the lakes for water activities (e.g. } \\
\text { swimming, fishing, skating) }\end{array}$ & $\begin{array}{l}\text { Communal grilling, fire pit, and/or picnic areas for } \\
\text { social interactions }\end{array}$ \\
\hline 5 & $\begin{array}{l}\text { Accessing outdoor gyms, running trails, } \\
\text { prepared climbing routes }\end{array}$ & $\begin{array}{l}\text { Areas where kids can play (e.g. playgrounds, } \\
\text { sandboxes, etc.) }\end{array}$ \\
\hline 6 & $\begin{array}{l}\text { Using paved pathways to walk or jog on instead } \\
\text { of dirt or grass }\end{array}$ & $\begin{array}{l}\text { Access to water (e.g. water play area, small pool, } \\
\text { fountain, pond, etc.) }\end{array}$ \\
\hline 7 & $\begin{array}{l}\text { Meeting and spending time with family and/or } \\
\text { friends }\end{array}$ & Public gardening area for general use \\
\hline 8 & $\begin{array}{l}\text { Using physical structures (like an observation } \\
\text { deck or wildlife tower) to have a good view of } \\
\text { wildlife and enjoy nature }\end{array}$ & $\begin{array}{l}\text { The beauty of untouched nature and wilderness (e.g. } \\
\text { forest areas, wildflower fields, etc.) }\end{array}$ \\
\hline 9 & $\begin{array}{l}\text { Spending time in the forest areas, more than in } \\
\text { the open landscapes }\end{array}$ & $\begin{array}{l}\text { The visual appeal of a diversified landscape (e.g. } \\
\text { mix of trees, bushes, water features) }\end{array}$ \\
\hline 10 & $\begin{array}{l}\text { Having seating opportunities (e.g. picnic tables, } \\
\text { benches, observation decks) }\end{array}$ & The beauty of well-kept flower beds \\
\hline 11 & $\begin{array}{l}\text { Access to water and the opportunity to spend } \\
\text { time on the beach and/or along the shorelines }\end{array}$ & $\begin{array}{l}\text { Watching birds, bees, butterflies and other wild } \\
\text { animals }\end{array}$ \\
\hline 12 & $\begin{array}{l}\text { Having the possibility to rent gear for outdoor } \\
\text { activities (e.g. climbing, water activities, } \\
\text { biking) }\end{array}$ & Well-maintained, healthy fields \\
\hline 13 & The beauty of untouched nature and wilderness & $\begin{array}{l}\text { Learning about plants and animals through e.g. } \\
\text { information boards or signs }\end{array}$ \\
\hline 14 & $\begin{array}{l}\text { Having no visible buildings, reduced traffic } \\
\text { noise, and feeling like I'm far from the city }\end{array}$ & $\begin{array}{l}\text { Environmental education through interactive } \\
\text { courses, nature walks, etc. }\end{array}$ \\
\hline 15 & $\begin{array}{l}\text { Learning about nature and wildlife through e.g. } \\
\text { information boards/signs or guided tours }\end{array}$ & Having quiet and peaceful areas in nature \\
\hline 16 & $\begin{array}{l}\text { Having outdoor educational opportunities } \\
\text { provided for kids and youth }\end{array}$ & $\begin{array}{l}\text { The feeling of privacy (e.g. through trees, high } \\
\text { bushes, etc.) }\end{array}$ \\
\hline 17 & Having quiet, peaceful areas in nature & $\begin{array}{l}\text { Being in nature to reduce stress and take a break } \\
\text { from my normal daily activities }\end{array}$ \\
\hline 18 & Exercising my "right to roam" & $\begin{array}{l}\text { Seeing familiar kinds of plants and animals that I } \\
\text { grew up with }\end{array}$ \\
\hline 19 & $\begin{array}{l}\text { Historical aspects of the park, like the ancient } \\
\text { remains and old oaks and pines }\end{array}$ & $\begin{array}{l}\text { Having seating opportunities (e.g. picnic tables, } \\
\text { benches, etc.) }\end{array}$ \\
\hline 20 & $\begin{array}{l}\text { Completing everyday activities, like } \\
\text { commuting to work, jogging, or walking } \\
\text { the dog }\end{array}$ & Good lighting after dark \\
\hline 21 & $\begin{array}{l}\text { Having more entrances into the park than are } \\
\text { currently available }\end{array}$ & Areas shaded by trees \\
\hline 22 & $\begin{array}{l}\text { Good signage and maps about how to get to the } \\
\text { reserve from the surrounding area }\end{array}$ & $\begin{array}{l}\text { Wide accessible paths for e.g. prams, wheelchairs } \\
\text { and walkers }\end{array}$ \\
\hline 23 & Good lighting after dark & $\begin{array}{l}\text { Sufficient rubbish bins for e.g. garbage and dog } \\
\text { poop }\end{array}$ \\
\hline 24 & $\begin{array}{l}\text { Having access to restrooms and day cabins that } \\
\text { are open all year }\end{array}$ & Event areas for e.g. Octoberfest, small concerts etc. \\
\hline 25 & $\begin{array}{l}\text { Having access to shops where I can buy snacks, } \\
\text { food and drinks }\end{array}$ & $\begin{array}{l}\text { Open areas for activities such as frisbee, football, } \\
\text { kite boarding, yoga, etc. }\end{array}$ \\
\hline
\end{tabular}


Each statement was printed individually together with its ID number (see Table 1), laminated for robustness, and secured with small Velcro squares to enable easy adjustments on the Q-matrix by the respondents during the sorting process. Each participant also provided socio-economic information (see Table 2) to provide context in a later analysis of the user groups. The results were analysed by applying an inverted factor analysis via Q-sorting software (Ken-Q analysis, (C2018 Shawn Banasick).

\section{RESULTS}

\subsection{Demographics}

A total of 227 individuals participated in the study (Flaten P-set=147; Halle Neustadt $\mathrm{P}$-set=80). In Flaten, over half of the P-set is female and the vast majority is either employed or retired, with over a third of participants over 60 years of age. In Halle Neustadt, over half of the P-set is female and a third over the age of 60, similar to the Stockholm P-set. However, unemployment is much higher in the Halle Neustadt P-set, with a fifth of people in search of employment compared to $1 \%$ of people interviewed in Flaten. Further characteristics of respondents in each P-set are outlined in Table 2 below.

Table 2: Selected characteristics of interviewees Halle Neustadt and Flaten.

\begin{tabular}{|c|c|c|}
\hline \multirow{2}{*}{ Demographic characteristics } & \multicolumn{2}{|c|}{ Case study } \\
\cline { 2 - 3 } & Flaten & Halle Neustadt \\
\hline \multicolumn{3}{|c|}{ Gender } \\
\hline \% of female & $53 \%$ & $58 \%$ \\
\hline$\%<20$ years & $15 \%$ & $18 \%$ \\
\hline$\% 21-40$ years & $23 \%$ & $34 \%$ \\
\hline$\% 41-60$ years & $26 \%$ & $14 \%$ \\
\hline$\%>60$ years & $36 \%$ & $34 \%$ \\
\hline \multicolumn{2}{|c|}{ Employment } \\
\hline$\%$ Student & $17 \%$ & $26 \%$ \\
\hline$\%$ Employed & $1 \%$ & $20 \%$ \\
\hline$\%$ Retired & $52 \%$ & $22 \%$ \\
\hline \% with children & $30 \%$ & $32 \%$ \\
\hline$\%$ with dogs & $38 \%$ & $26 \%$ \\
\hline$\%$ on bike & $14 \%$ & $20 \%$ \\
\hline & $47 \%$ & $38 \%$ \\
\hline
\end{tabular}

\subsection{Dominant profiles per case study site}

The web application Ken-Q Analysis was selected to process the 227 collected Q-sorts, separated and individually analysed by case study site. While this paper will not go into the details of using the application, we instead focus on the means by which the results were obtained and their interpretation and implications.

The analysis of the data through Ken-Q Analysis is based on factor analysis, where the variables are the totality of the Q-sorts made by participants rather than each of the individual statements. This is because the goal of factor analysis of Q data is to simplify participants' 
perspectives as factors/components that indicate common attitudes of the investigated participants. Factor rotation and flagging of Q-sorts identified four different factors for each case study site (Flaten and Halle Neustadt) that were deemed reliable in terms of representation of a group of subjects and the exact nature of the viewpoint.

Each of the four identified factors per case study site represents a group of statements that show similarity in terms of sorting priorities (i.e., personal value). For each factor, the most and least valued elements of green and blue infrastructure common across individuals of the specific factor (see Fig. 2) served to form a profile. Each of these four profiles is further described by a narrative describing the features which are shared as the "ideal" by statements within this factor profile. The main factor profiles and their associated narratives are presented in Tables 3 and 4 for Flaten and Halle Neustadt, respectively.

\subsection{Elements most and least valued across user groups}

The four profiles for each case study site identified the different ways in which site stakeholders prioritise aspects of green and blue infrastructure. It is important to note that while the Q-sort statements in each city addressed similar GBI considerations, the specific factors uncovered for each city are different. This insight represents one of the strengths of Q-methodology: policy makers are made aware of and can take the range of different subjective valuations into consideration when making planning decisions about a specific location. While this information provides valuable insights for the blue and green infrastructure planning process, we conducted further analyses to identify which elements are shared across all factors. The identification of shared highly valued elements allows
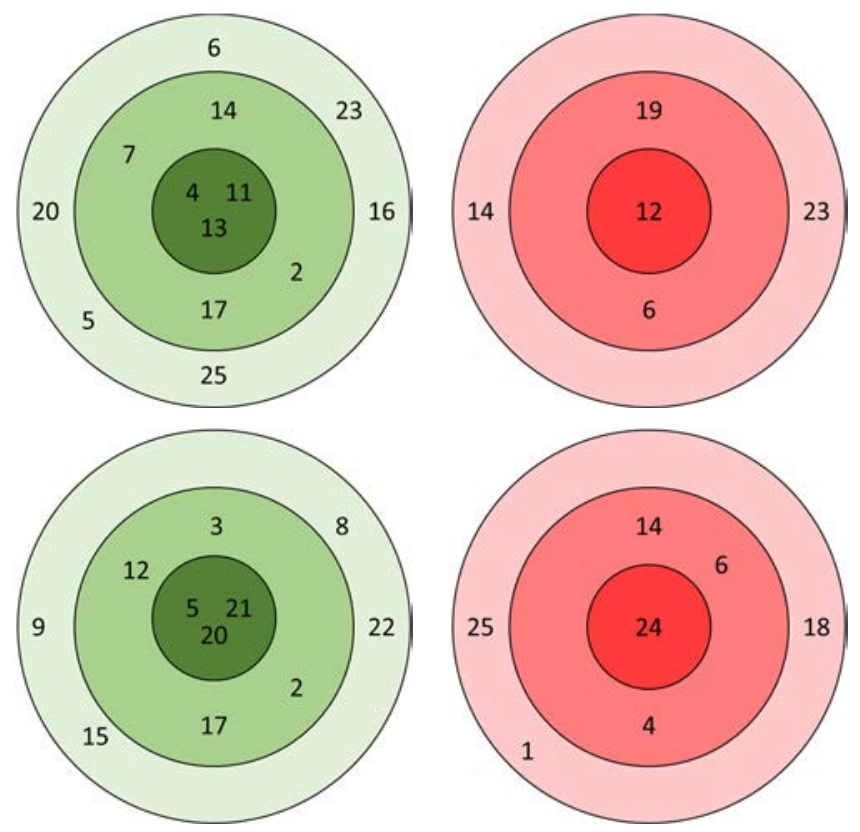

Figure 2: Statements of GBI elements most (left) and least (right) valued across all user groups in the case study Flaten (top row) and Halle Neustadt (bottom row). Statements correspond to IDs presented in Table 1, Methodology section. 
Table 3: Main factor profiles for the Flaten case study.

\begin{tabular}{|c|l|l|}
\hline Factor & Factor profile & Narrative \\
\hline 1 & Wild nature & $\begin{array}{l}\text { value the more "wild" and unmanaged areas to } \\
\text { escape the city and noise and find solitude }\end{array}$ \\
\hline 2 & Comfortable nature & $\begin{array}{l}\text { value areas and amenities that are in close } \\
\text { proximity to nature, but which are rather grey than } \\
\text { green or blue features }\end{array}$ \\
\hline 3 & $\begin{array}{l}\text { Affordable and social } \\
\text { nature }\end{array}$ & $\begin{array}{l}\text { enjoy simple and inexpensive social activities } \\
\text { outside }\end{array}$ \\
\hline 4 & Well-maintained nature & $\begin{array}{l}\text { wants to execute daily physical activities, such as } \\
\text { walking and jogging in well-maintained } \\
\text { surroundings }\end{array}$ \\
\hline
\end{tabular}

Table 4: Main factor profiles for the Halle Neustadt case study.

\begin{tabular}{|c|l|l|}
\hline Factor & Factor profile & Narrative \\
\hline 1 & Managed nature & $\begin{array}{l}\text { value grey infrastructure features which allow for } \\
\text { physical and social activities }\end{array}$ \\
\hline 2 & Wild and calming nature & $\begin{array}{l}\text { value resemblance of untouched, "wild" nature as } \\
\text { calming sanctuary from everyday life }\end{array}$ \\
\hline 3 & Comfortable nature & $\begin{array}{l}\text { appreciate nature for its ability to calm, de-stress } \\
\text { and provide privacy while being well managed }\end{array}$ \\
\hline 4 & Social nature & $\begin{array}{l}\text { view green areas as an exciting opportunity to meet } \\
\text { friends and family, and to engage in various social } \\
\text { activities }\end{array}$ \\
\hline
\end{tabular}

planners to identify ways in which to simultaneously appeal to the greatest number of a specific site's stakeholders while avoiding appeals likely to "turn-off" significant groups of stakeholders (as reflected in the shared least valued statements). For this, statements that were deemed most positive and most negative across all profiles were tallied in their subjective valuation and rated from highest to lowest scores.

In Stockholm's green area of Flaten, for example, the elements valued most across all four factor profiles are the "beauty of untouched nature", "access to water and the opportunity to spend time on the beach or along", and the use of "lakes for water activities (e.g. swimming, fishing, skating)". Meanwhile, users across all identified profiles least valued the possibility to "rent gear for outdoor activities" (see Fig. 2). In Halle Neustadt, user groups most valued "areas where kids can play", "areas shaded by trees", and "good lighting after dark", while all agreed that the area should not be converted into an event space.

\section{DISCUSSION}

\subsection{Capturing the diversity of citizen preferences}

Our research shows that the Q-method can be successfully adapted to site-specific conditions and applied to capture the diversity of preferences in a given area with regard to green and blue infrastructure. Instead of focusing on specific demographic groups or individuals, the Q-method draws attention to the variety of viewpoints within the sample group and is able to 
highlight dominant profiles and their preferences as input to location-specific planning or decision-making processes.

Reflecting on the competing interests and power struggles that exist between different stakeholders in the creation and use of urban green areas, the Q-method reveals areas of agreements and disagreements within different profile groups and highlights each profile's narrative to better portray existing diversity. A second analysis (i.e. identifying shared preferences and less valued features across all user profiles) enables a representation of the points of agreement the different user and stakeholder groups and encompasses the full spectrum of demographics such as elderly or young people, families etc. for consideration in decision-making processes.

The result of the two analyses is an identification of (GBI) features in a given area which can be prioritised or left out of planning processes for (re)developing the space. These insights about citizen preferences can be also looked at alongside existing development plans to reveal discrepancies and feed into the reshaping of plans, priorities and decision-making.

\subsection{More inclusive, effective and efficient urban planning}

Shrinking public funds, an increasing diversity of viewpoints amongst citizens and growing societal challenges facing cities necessitate changes be made to urban planning processes. In particular, there is an urgency to treat local communities as critical stakeholders, enablers and future users of GBI [30], and integrate their preferences into decision-making and planning to ensure effective, inclusive and efficient planning. Active community participation in GBI design and implementation ensures that decision-makers have access to better knowledge and awareness about different user viewpoints. This in turn enables them to make more informed and publicly supported decisions, preventing negative responses such as community protests, damage to the GBI, or low use of the area. Inclusive planning processes utilising tools such as the Q-methodology also serve to enhance the development and accessibility of GBI for citizens [29].

Adequate involvement of current and potential future green space users in planning processes can also lead to indirect environmental and social benefits for the residents and the city as a whole. Such impact could include, for example, environmental awareness raising; in Halle Neustadt, many users acknowledged the problem of trash and expressed interest in supporting a cleaner, trash-free environment. Integrating results from preference assessments such as the Q-method into GBI planning can help to instil a sense of ownership for a specific place and create opportunities to involve citizens in maintenance activities (e.g. "we helped design this space, so it belongs to us and we ensure that it is not damaged"). This potential to foster community action for GBI maintenance has been revealed by different studies (e.g. [31], [32]) and offers a significant potential to relieve burdens on public funds regarding the long-term maintenance of GBI.

The Q-method also addresses issues such as social equity and environmental justice. The approach is valuable for its inclusion of the preferences and viewpoints of individuals who might be negatively affected by decisions concerning the planning of urban areas (e.g. via increasing environmental air pollution, loss of urban green spaces, decline in human well-being or green gentrification). Additional data gathered on, for example, demographics, visiting frequency or distance of their home to the area can also inform urban planning projects on priorities for the development and design of GBI.

The implementation of the Q-method in Flaten and Halle Neustadt shows a high adaptability to diverse local conditions and to different physical sizes of the studied areas. These variations can be easily addressed by the design of the implementation (e.g. selection 
of locations and times to conduct the method). The Q-method has been also proven to be very inclusive to capture the views of a large range of stakeholders characterised by different multicultural backgrounds.

\section{CONCLUSIONS}

This study provides evidence to support the integration of user preferences into urban planning processes. The Q-method in particular is shown to be a valuable tool to effectively design publicly supported green and blue infrastructure, addressing the shared responsibility by citizens and policy makers alike for environmental policy making and planning. Yet while the Q-methodology enables all interested individuals in a given area to participate, there are several logistical challenges associated with its application that must be considered in its design and implementation to ensure optimal results. In the case of areas with diverse demographics, such as mixes of employed and unemployed individuals, different primary languages being spoken, and limited mobility of citizens, the Q-setup needs to take account of these features. Here, it would be advisable to provide translations of the Q-statements in multiple languages, to visit the site at various times of day and to conduct the fieldwork on weekends and weekdays over the course of at least a week.

The aspect of scale is also a consideration when applying the Q-method to gather information on the variety of perspectives regarding GBI planning. While it is valuable for deciding on the design of site-specific GBI (i.e. which elements to put in a community green space), it is likely less effective in deciding on a municipal policy strategy. Including community participation in a meaningful way in high-level discussions at city level thus remains a challenge which would benefit from further research, particularly looking at which other methodological approaches could complement or be an alternative to the Q-method.

Further research is deemed necessary to identify solutions and enable a wider uptake of the $\mathrm{Q}$ and other methods targeting the incorporation of public viewpoints into decision-making. A specific area of research which can complement this study is to explore how to practically integrate results into ongoing processes. This also includes developing concrete approaches for effectively closing the gap between what users want and policy makers' agendas given that the value of the Q-method lies not in gathering insights on user preferences, but rather in their integration and uptake of results into ongoing municipal decision-making and planning processes.

\section{ACKNOWLEDGEMENTS}

This research was funded through the 2015-2016 ERA-Net BiodivERsA COFUND call for research proposals and was conducted within the on-going BiodiveERsA research project ENABLE ("Enabling Green and Blue Infrastructure Potential in Complex Social-Ecological Regions", 2017-2020). We would like to thank the participants of the Q-method for their time, the colleagues in the ENABLE project leading the Halle and Stockholm case studies for their inputs to the design and implementation of this research, and local partners in each region for their support in developing the Q-statements and logistical help. A special thanks to Elena von Sperber for her energy and invaluable contributions to both case studies. Finally, we are extremely grateful to Dr. Joel Davis for his invaluable comments and feedback regarding the study design, data analysis and article conceptualisation and for being a great support throughout the drafting process. 


\section{REFERENCES}

[1] European Commission, Europa, EU population up to nearly 513 million on 1 January 2018, News release, Eurostat. https://ec.europa.eu/eurostat/documents/2995521/ 9063738/3-10072018-BP-EN.pdf/ccdfc838-d909-4fd8-b3f9-db0d65ea457f. Accessed on: 7 Jul. 2019.

[2] European Commission, Europa, People in the EU - population projections, Eurostat, https://ec.europa.eu/eurostat/statistics-explained/index.php/People_in_the_EU_ population projections\#Population_projections. Accessed on: $7 \mathrm{Jul} .2019$.

[3] United Nations, Department of Economic and Social Affairs, Population Division, World Population Prospects: The 2009 Revision, United Nations: New York, pp. 912, 2010.

[4] Haaland, C. \& van den Bosch, C.K., Challenges and strategies for urban green-space planning in cities undergoing densification: A review. Urban Forestry \& Urban Greening, 14(4), pp. 760-771, 2015.

[5] Soga, M. \& Gaston, K.J., Extinction of experience: Evidence, consequences and challenges of loss of human-nature interactions. Frontiers in Ecology and the Environment, 14, pp. 94-101, 2016.

[6] Artmann, M. et al., The role of urban green spaces in care facilities for elderly people across European cities. Urban Forestry \& Urban Greening, 27, pp. 203-213, 2017.

[7] Hansmann, R., Hug, S.-M. \& Seeland, K., Restoration and stress relief through physical activities in forests and parks. Urban Forestry \& Urban Greening, 6(4), pp. 213-225, 2007.

[8] Hartig, T., Mitchell, R., de Vries, S. \& Frumkin, H., Nature and health. Annual Review of Public Health, 35(1), pp. 207-228, 2014.

[9] Kabisch, N., Qureshi, S. \& Haase, D., Human-environment interactions in urban green spaces: A systematic review of contemporary issues and prospects for future research. Environmental Impact Assessment Review, 50, pp. 25-34, 2015.

[10] Merckx, T. et al., Body-size shifts in aquatic and terrestrial urban communities. Nature, 558(7708), pp. 113-116, 2018.

[11] Sadler, J., Bates, A., Hale, J. \& James, P., Bringing cities alive: the importance of urban green spaces for people and biodiversity. Urban Ecology (Ecological Reviews), ed. K. Gaston, Cambridge University Press: Cambridge, pp. 230-260, 2010.

[12] Seto, K.C., Güneralp, B. \& Hutyra, L.R., Global forecasts of urban expansion to 2030 and direct impacts on biodiversity and carbon pools. Proceedings of the National Academy of Sciences of the United States of America, 109, pp. 16083-16088, 2012.

[13] Smith, T., Nelischer, M. \& Perkins, N., Quality of an urban community: A framework for understanding the relationship between quality and physical form. Landscape and Urban Planning, 39(2-3), pp. 229-241, 1997.

[14] Lin, B., Meyers, J. \& Barnett, G., Understand the potential loss and inequities of green space distribution with urban densification. Urban Forestry \& Urban Greening, 14(4), pp. 952-958, 2015.

[15] Gill, S.E., Handley, J.F., Ennos, A.R. \& Pauleit, S., Adapting cities to climate change: The role of the green infrastructure. Built Environment, 33(1), pp. 115-133, 2007.

[16] Bäcklund, P. \& Mäntysalo, R., Agonism and institutional ambiguity: Ideas on democracy and the role of participation in the development of planning theory and practice - The case of Finland. Planning Theory, 9(4), pp. 333-350, 2010.

[17] Evans, J.P., Wildlife corridors: An urban political ecology. Local Environment, 12(2), pp. 29-152, 2007. 
[18] Faehnle, M., Bäcklund, P., Tyrväinen, L., Niemelä, J. \& Yli-Pelkonen, V., How can residents' experiences inform planning of urban green infrastructure? Case Finland. Landscape and Urban Planning, 130, pp. 171-183, 2014.

[19] Kronenberg, J., Why not to green a city? Institutional barriers to preserving urban ecosystem services. Ecosystem Services, 12, pp. 218-227, 2015.

[20] Lafortezza, R., Davies, C., Sanesi, G. \& Konijnendijk, C.C., Green Infrastructure as a tool to support spatial planning in European urban regions. iForest, 6, pp. 102-108, 2013.

[21] Tsantopoulos, G., Varras, G., Chiotelli, E., Fotia, K. \& Batou, M., Public perceptions and attitudes toward green infrastructure on buildings: The case of the metropolitan area of Athens, Greece. Urban Forestry \& Urban Greening, 34, pp. 181-195, 2018.

[22] European Commission, Green Infrastructure (GI): Enhancing Europe's Natural Capital. Communication from the Commission to the European Parliament, The Council, The European Economic and Social Committee and the Committee of the Regions, Brussels, 6.5.2013COM(2013) 249 final, 2013.

[23] Benedict, M.A. \& McMahon, E.T., Green infrastructure: smart conservation for the 21st century. Renewable Resour. J., 20, pp. 12-17, 2002.

[24] Salomaa, A., Paloniemi, R., Kotiaho, J.S., Kettunen, M., Apostolopoulou, E. \& Cent, J., Can green infrastructure help to conserve biodiversity? Environment and Planning, 35(2), pp. 265-288, 2016.

[25] Roe, M. \& Mell, I., Negotiating value and priorities: evaluating the demands of green infrastructure development. Journal of Environmental Planning and Management, 56(5), pp. 650-673, 2013.

[26] Gómez-Baggethun, E. \& Ruiz-Perez. M., Economic valuation and the commodification of ecosystem services. Progress in Physical Geography, 35, pp. 613628, 2011.

[27] Wang, Y., Kotze, D.J. \& Niemela, J., What makes urban greenspace unique? Relationships between citizens' perceptions on unique urban nature, biodiversity and environmental factors. Urban Forestry \& Urban Greening, 42, pp. 1-9, 2019.

[28] Kamal, S., Kocor, M. \& Grodzinska-Jurczak, M., Quantifying human subjectivity using Q-method: When quality meets quantity. Qualitative Sociology Review, X(3), pp. 60-79, 2014.

[29] Buchel, S. \& Frantzeskaki, N., Citizens' voice: A case study about perceived ecosystem services by urban park users in Rotterdam, The Netherlands. Ecosystem Services, 12, pp. 169-177, 2015.

[30] Greenwood, M.R., Community as a stakeholder. Focusing on corporate social and environmental reporting. The Journal of Corporate Citizenship, 4, pp. 31-45, 2001.

[31] Nikolaidou, S., Klöti, T., Tappert, S. \& Drilling, M., Urban gardening and greenspace governance: Towards new collaborative planning practices. Urban Planning, 1(1), pp. 5-19, 2016.

[32] Wilker, J., Rushe K. \& Rymsa-Fitschen, C., Improving participation in green infrastructure planning. Planning Practice and Research, 31(3), pp. 229-249, 2016. 